\title{
Various phosphodiesterase subtypes mediate the in vivo antilipolytic effect of insulin on adipose tissue and skeletal muscle in man
}

\author{
S. Enoksson ${ }^{1}$, E.Degerman ${ }^{2}$, E.Hagström-Toft ${ }^{2}$, V.Large ${ }^{3}$, P.Arner ${ }^{3}$ \\ ${ }^{1}$ Department of Vascular Surgery, Huddinge University Hospital, Karolinska Institute, Huddinge, Sweden \\ ${ }^{2}$ Department for Cell and Molecular Biology, Section for Molecular Signalling, Lund University, Lund, Sweden \\ ${ }^{3}$ Department of Medicine and Research Center, Huddinge University Hospital, Karolinska Institute, Huddinge, Sweden
}

\begin{abstract}
Summary The antilipolytic effect of insulin on human abdominal subcutaneous adipose tissue and skeletal muscle during local inhibition of cAMP-phosphodiesterases (PDEs) was investigated in vivo, by combining microdialysis with a euglycaemic, hyperinsulinaemic clamp. During hyperinsulinaemia, the glycerol concentration decreased by $40 \%$ in fat and by $33 \%$ in muscle. Addition of the selective PDE3-inhibitor amrinone abolished the insulin-induced decrease in adipose glycerol concentration, but did not influence the glycerol concentration in skeletal muscle. Nor did the PDE4-selective inhibitor rolipram or the PDE5-selective inhibitor dipyridamole influence the insulin-induced decrease in muscle tissue glycerol. However, the non-selective PDE-inhibitor
\end{abstract}

theophylline counteracted the antilipolytic action of insulin at both sites. The specific activity of PDEs was also determined in both tissues. PDE3-activity was $36.8 \pm 6.4 \mathrm{pmol} \times \mathrm{min}^{-1} \times \mathrm{mg}^{-1}$ in adipose tissue and $3.9 \pm 0.5 \mathrm{pmol} \times \mathrm{min}^{-1} \times \mathrm{mg}^{-1}$ in muscle. PDE4activity in skeletal muscle was high, i.e., $60.7 \pm 10.2$ pmol $\times \min ^{-1} \times \mathrm{mg}^{-1}$ but $8.5 \mathrm{pmol} \times \mathrm{min}^{-1} \times \mathrm{mg}^{-1}$ or less in adipose tissue. In conclusion, insulin inhibits lipolysis in adipose tissue and skeletal muscle by activation of different PDEs, suggesting a unique metabolic role of muscle lipolysis. [Diabetologia (1998) 41: 560-568]

Keywords Microdialysis, glycerol, interstitial flow, phosphodiesterase inhibitors.
The mechanism involved in insulin stimulation of glucose metabolism has been thoroughly investigated. Much less is known about the action of insulin on lipid metabolism. Insulin inhibits lipolysis in adipose tissue as a result of dephosphorylation of adipocyte hormone-sensitive lipase (HSL). This enzyme is the ratelimiting step in lipolysis and catalyses the breakdown of triglycerides to non-esterified fatty acids and glycerol [1]. The major mechanism for this antilipolytic effect of insulin is stimulation of a particular subtype

Received: 1 October 1997 and in revised form: 22 December 1997

Corresponding author: Dr. S. Enoksson, Department of Vascular Surgery, K53, HLK-Division, Huddinge University Hospital, S-141 86 Huddinge, Sweden

Abbreviations: PDE, Phosphodiesterase; HSL, hormone sensitive lipase; c. v., coefficient of variation; ANOVA, analysis of variance; BSA, bovine serum albumin. (i.e., type-3) phosphodiesterase (PDE3) [2]. PDE3 breaks down cyclic AMP to inactive 5 '-AMP so that less HSL is phosphorylated.

Many PDE isoenzymes with various functions, tissue localizations and regulations have been discovered [3]. Seven genes have so far been identified coding for different PDEs. In addition, subclasses in the isoenzymes have been identified. Hitherto, PDE3 was the only isoenzyme that has been shown to be regulated by insulin. Using microdialysis, we recently investigated the role of PDE3 in the antilipolytic effect of insulin on human adipose tissue in vivo [4]. Insulin-induced antilipolysis was found to be completely counteracted by selective local inhibition of PDE3, indicating that PDE3 inhibition is the major in vivo mechanism for insulin's antilipolytic effect.

It is generally considered that active lipolysis mainly takes place in adipose tissue. However, a striking and active lipolysis process, which could be inhibited by insulin, has recently been demonstrated in hu- 
man skeletal muscle in vivo [5]. The mechanism underlying this effect of insulin is unknown. Furthermore, Holm et al. [6] demonstrated small but significant quantities of HSL in rat skeletal muscle, 1-2\% of the amount in adipose tissue. This lipase has been purified from bovine heart muscle and isolated rat myocytes, and it has been shown to be activated by a cAMP-dependent protein kinase in much the same way as in adipocytes [7]. On the other hand, no detectable amounts of PDE3 have been found in canine or rabbit skeletal muscle [8].

Bearing in mind the possible metabolic importance of lipolysis in skeletal muscle, we compared the role of phosphodiesterases in insulin's antilipolytic effect on adipose and muscle tissues of man in vivo. Subcutaneous adipose tissue and skeletal muscle of healthy non-obese volunteers were microdialysed simultaneously before and during a hyperinsulinaemic, euglycaemic clamp. Glycerol concentration (lipolysis index) and ethanol escape (index of interstitial flow) were monitored. The effects of selective and non-selective phosphodiesterase inhibitors were also studied. Furthermore, the enzymatic activities of HSL and various PDEs were determined in homogenates from the two tissues.

\section{Subjects and methods}

Subjects. Insulin infusion combined with microdialysis experiments were performed in ten healthy and drug-free non-obese (BMI ranging from 18 to $26 \mathrm{~kg} / \mathrm{m}^{2}$, median $21 \mathrm{~kg} / \mathrm{m}^{2}$ ) volunteers (five men and five women), median age 31 (range 26-49) years. Tissue biopsies were collected from another eight subjects (three men and five women), median age 74 (range 64-88) years who underwent various open vascular procedures. All subjects gave their informed consent. The study was approved by the Karolinska Institute ethics committee.

Microdialysis. The microdialysis technique and equipment have been described in detail earlier $[4,9,10]$. Briefly, a tubular polyamide dialysis membrane $(0.62 \times 30 \mathrm{~mm}, 20000 \mathrm{Da}$ cut-off) is glued to the end of the outer cylinder of a concentric double-lumen polyurethane tubing. The perfusate was propelled by a CMA/100 microinfusion pump (CMA Medical, Stockholm, Sweden $)$ at a continuous rate $(2.0 \mu \mathrm{l} / \mathrm{min})$ and flowed through the outer tubing into the space between the concentric cylinders to the distal end of the probe. The exchange of molecules between the interstitial fluid and the perfusate occurred across the semipermeable dialysis membrane, after which the medium entered the inner cannula in a retrograde direction and was collected in timed fractions for the analyses of glycerol and ethanol. Changes in glycerol reflect lipolysis and are discussed in detail elsewhere [11]. Glycerol is not reutilized to any large extent in adipose tissue but in skeletal muscle some glycerol may combine with non-esterified fatty acids to form triglycerides, as discussed [5]. On the other hand, in both tissues, the production of glycerol is larger than the utilization. Changes in the ratio of the ethanol concentration in the outgoing and ingoing dialysis media reflect changes in the interstitial flow of the tissues surrounding the microdialysis probe, as recently discussed [12]. The interstitial flow, in turn, is regulated by the blood flow. It has recently been shown in human skeletal muscle and subcutaneous adipose tissue that changes in local blood flow, as measured with the xenon wash-out technique, are strongly correlated with changes in local interstitial flow, as measured with the microdialysis ethanol method [13, 14]. When changes in interstitial flow and glycerol concentration are considered together, fluctuations in the lipolysis rate can be evaluated more precisely [11].

Experimental protocol. The subjects were examined in the supine position in the morning after an overnight fast. Following local skin anaesthesia (EMLA, Astra, Södertälje, Sweden), microdialysis probes were introduced percutaneously into the left and right gastrocnemius muscles. Probes were also placed in the abdominal subcutaneous fat to the left and right of the umbilicus. The distance between probes was $50 \mathrm{~mm}$. The aim was to use five adipose and five muscle probes simultaneously. However, due to technical problems, including discomfort, we were obliged to use fewer probes in several subjects at any given time. Instead, these subjects were re-examined later when the studies were completed. The basal dialysate perfusion fluid was Ringer's solution (sodium $1.5 \times 10^{-1} \mathrm{~mol} / \mathrm{l}$, potassium $4 \times 10^{-3} \mathrm{~mol} / 1$, calcium $2.3 \times 10^{-3} \mathrm{~mol} / \mathrm{l}$, chloride $1.6 \times 10^{-1} \mathrm{~mol} /$ 1) with $50 \times 10^{-3} \mathrm{~mol} / \mathrm{l}$ ethanol (Vin \& Spritcentralen, Stockholm, Sweden). Five probe systems were used in each patient. One system included the Ringer-ethanol solution alone (control). In the second probe system, $10^{-3} \mathrm{~mol} / \mathrm{l}$ of the PDE3-selective inhibitor amrinone (Sterling-Winthrop, New York, N. Y., USA) was added to the Ringer-ethanol solution. The third probe in each tissue was perfused with basal solution plus $10^{-2}$ $\mathrm{mol} / \mathrm{l}$ of the non-selective PDE-inhibitor theophylline (Draco AB, Lund, Sweden). The fourth probe system was perfused with $10^{-4} \mathrm{~mol} / \mathrm{l}$ of the PDE4-selective inhibitor rolipram ( Schering $\mathrm{AG}$, Berlin, Germany) and the fifth probe was perfused $10^{-3} \mathrm{~mol} / \mathrm{l}$ of the PDE5-selective inhibitor dipyridamole (Boehringer Ingelheim, Ingelheim, Germany). The drugs were added in the perfusate during the full time of the experiment. The concentrations of amrinone and theophylline which were used have previously been shown to induce a maximal lipolytic effect on adipose tissue in situ in microdialysis experiments [15]. As regards dipyridamole, we used a concentration which is 1000 times higher than the half-maximum effective concentration for the agent's inhibitory effect on PDE5 in vitro [16]. The concentrations of PDE-inhibitors used in this study may seem high at first glance. However, it should be born in mind, first, that recovery is about $10 \%$ with the present dialysis flow velocity and second, there is a further unknown dilution of the drug as soon as it enters the tissue [17]. Thus, the concentration at the cellular level would be at least 100 times lower than the in going concentration. Microdialysis samples were collected every $15 \mathrm{~min}$. At the start of the study, a cannula was inserted retrogradely into a vein in the back of the right hand, which was placed in a heated box for sampling of arterialized blood [18]. Arterialization was confirmed by blood gas analysis ( $>95 \% \mathrm{O}_{2}$ saturation). Another intravenous catheter was inserted in the contralateral antecubital vein for the infusion of insulin and glucose.

Insulin infusion. After 60 min of baseline dialysate sampling and repeated baseline plasma samples, insulin was infused at $40 \mathrm{mU} \times \mathrm{m}^{-2} \times \mathrm{min}^{-1}$ for $135 \mathrm{~min}$, including a short priming period [19]. Arterialized blood was collected at $5 \mathrm{~min}$ intervals for measurements of glucose (HemoCue, HemoCue AB, Ängelholm, Sweden), and varying amounts of $20 \%$ glucose were infused to attain euglycaemia.

Assay of hormone-sensitive lipase activity. The assay was performed as described previously [20,21]. Specimens of human 
gastrocnemius muscle $(300 \mathrm{mg})$ and overlying subcutaneous adipose tissue $(800 \mathrm{mg})$ were homogenized in $0.6 \mathrm{ml}$ of a buffer containing $0.25 \mathrm{~mol} / \mathrm{l}$ sucrose, $1 \mathrm{mmol} / \mathrm{l}$ EDTA, $1 \mathrm{mmol} / 1 \mathrm{di}-$ thioerythritol and the protease inhibitors leupeptin and antipain, both at $20 \mu \mathrm{g} / \mathrm{ml}$ and pepstatin $1 \mu \mathrm{g} / \mathrm{ml}$. The samples were centrifuged at $12000 \times g$ for $3 \mathrm{~h}$ at $4{ }^{\circ} \mathrm{C}$ in an Eppendorf centrifuge 5403. The fat-free infranatant was recovered for analysis of enzymatic activity, which was determined using 1(3)-mono $\left[{ }^{3} \mathrm{H}\right]$ oleyl-2-olylglycerol as substrate. All samples were incubated in triplicates for $30 \mathrm{~min}$ at $37^{\circ} \mathrm{C}$. The reaction was interrupted and the labelled non-esterified fatty acids were isolated by addition of methanol-chloroform-heptane 1.41:1.25:1 (v:v:v) and $0.1 \mathrm{~mol} / 1$ potassium carbonate buffer $(\mathrm{pH}=10.5)$. After centrifugation for $20 \mathrm{~min}$ at $2000 \mathrm{rev} / \mathrm{min}$, an aliquot of the supernatant was collected for scintillation counting. Enzyme activity was defined as $1 \mathrm{nmol}$ of non-esterified acid released per min at $37^{\circ} \mathrm{C}$. Since the phosphorylated and the dephosphorylated forms of HSL have the same activity, the total amount of enzyme was activated. Lipase activity was related to the protein concentration of the infranatant, which was measured according to Bradford, using bovine serum albumin as a standard.

Assay of phosphodiesterase activity. Biopsies were taken from the gastrocnemius muscle and the adjacent subcutaneous adipose tissue and were frozen at $-80^{\circ} \mathrm{C}$. The samples were thawed on ice and minced in $3 \mathrm{ml}$ of homogenization buffer containing $50 \mathrm{mmol} / \mathrm{l}$ Tris $\mathrm{pH} 7.5,250 \mathrm{mmol} / \mathrm{l}$ sucrose, $1 \mathrm{mmol} / \mathrm{l}$ EDTA and $10 \mu \mathrm{g} / \mathrm{ml}$ protease inhibitors (leupeptin, antipain and pepstatin A) per $\mathrm{mg}$ tissue. The adipose tissue was homogenized with a glass homogenizer (20 strokes) and the skeletal muscle with a knife homogenizer (DIAX 699, 30 $\mathrm{s} \times 6)$. The homogenates were centrifuged at a low speed (10 $000 \mathrm{rev} / \mathrm{min}, 5 \mathrm{~min}$ ) to remove tissue debris. The low-speed supernatants were centrifuged at $100000 \mathrm{~g}$ for $60 \mathrm{~min}$. The pellets were resuspended in homogenization buffer. Pellets and supernatants were stored at $-80^{\circ} \mathrm{C}$. PDE- activity was defined as the amount of cAMP hydrolysed per min, determined according to Manganiello et al. [22] in a total volume of $300 \mu \mathrm{l}$, $50 \mathrm{mmol} / \mathrm{l}$ Hepes, pH 7.4, $0.1 \mathrm{mmol} / \mathrm{l}$ EDTA, $8.3 \mathrm{mmol} / \mathrm{l}$ $\mathrm{MgCl}, \quad 0.5 \mu \mathrm{mol} / \mathrm{l}$ cAMP, $1 \mu \mathrm{Ci}\left[{ }^{3} \mathrm{H}\right] \mathrm{cAMP} / \mathrm{ml}$. OPC 3911 (PDE3-inhibitor) and rolipram (PDE4-inhibitor) were used at 10 and $30 \mu \mathrm{mol} / 1$ respectively, in the assays to estimate PDE3 and PDE4 activities in the crude fractions. Proteins were measured in supernatants and pellets, using the Bradford method with BSA $(2-12 \mu \mathrm{g})$ as a standard.

Analysis of insulin and glucose. Plasma insulin was analysed using a commercial radioimmunoassay kit (Pharmacia Insulin RIA, Pharmacia-Upjohn,Uppsala, Sweden). The concentration of glucose in arterialized plasma was determined with a routine enzymatic method [23].

Analysis of glycerol. Ten microlitres of plasma or dialysate were used to analyse glycerol. We used an automatic ultrasensitive kinetic bioluminescence assay and a bioluminescent analyser for the assay of glycerol [24].

Analysis of ethanol. Ten microlitres of perfusate or dialysate was used to measure the ethanol concentration with an enzymatic fluorometric method [25].

Statistical analysis. For technical reasons including disruption of the dialysis membrane, five probes in adipose tissue and four in skeletal muscle did not produce adequate volumes and the data have been excluded from the statistical evaluation. We could not use more than four of the five probes simultaneously in each tissue of a single subject. In most cases, paired comparisons between treatments within the same subject could not therefore be made. One-factor analysis of variance (ANOVA) was used to determine differences in the mean basal glycerol or ethanol levels (i.e., mean of the three fractions preceding the insulin infusion). ANOVA repeated measures was used to determine significant changes in a single parameter over time. Two-factor ANOVA with repeated measures was performed to detect significant changes from basal values and differences between various treatments in the magnitude of change in values over time after insulin infusions. Differences between experiments at a particular timepoint were tested using one-factor ANOVA. A significant difference between means was determined with Scheffe's post-hoc test when an overall significance was indicated by the $F$-value. In cases where only two groups of values were compared in the same subjects, the Student's paired $t$-test was used. The coefficient of variation $(\mathrm{CV})$ was calculated as the standard deviation divided by the mean $\times 100(\%)$. Results are presented as means \pm SEM.

\section{Results}

Plasma glucose, glycerol and insulin. Changes in plasma glucose, glycerol and insulin levels during the experiment are shown in Figure 1. The arterialized plasma glucose concentration was stable throughout the insulin clamp, the coefficient of variation $(\mathrm{CV})$ being $4.5 \%$. Plasma-free insulin increased during the priming sequence to $419 \pm 16 \mathrm{pmol} / \mathrm{l}$ at $30 \mathrm{~min}$. Thereafter, a stable insulin concentration of about $386 \mathrm{pmol} / \mathrm{l}$ was obtained during the clamp, CV $5.1 \%$. The concentration of glycerol in arterialized blood was $57.5 \pm 6.5 \mu \mathrm{mol} / \mathrm{l}$ during basal conditions and decreased continuously $(F=19.6)$ during the insulin infusion to about $65 \%$ of the basal level.

Adipose tissue glycerol. The dialysis probes were perfused for $60 \mathrm{~min}$ before the insulin infusion started. Baseline values were calculated as the mean of the three fractions preceding initiation of the clamp at time zero. During perfusion with the control solution $(n=9)$, the baseline level of glycerol was $80.3 \pm 8.1 \mu \mathrm{mol} / \mathrm{l}$. The basal glycerol concentration with amrinone was $79.2 \pm 5.2 \mu \mathrm{mol} / \mathrm{l} \quad(n=8)$, with theophylline $124.4 \pm 12.2 \mu \mathrm{mol} / \mathrm{l}(n=8)$ and with rolipram $86.0 \pm 3.5 \mu \mathrm{mol} / \mathrm{l}(n=6)$. The basal level of glycerol in the theophylline probe differed significantly from that with all the other probes $(F=7.3$, $p=0.004)$. This was to be expected, since the presently used concentration of theophylline markedly stimulates lipolysis in vivo in microdialysis experiments [15]. However, the glycerol values in the control, amrinone, and rolipram probes did not differ significantly. Figure 2 depicts changes in glycerol concentrations in adipose tissue before and during the infusion of insulin, data being expressed as percentage change from the basal dialysate level in order to facilitate a comparison between various treatments. During systemic hyperinsulinaemic euglycaemia, the glycerol 

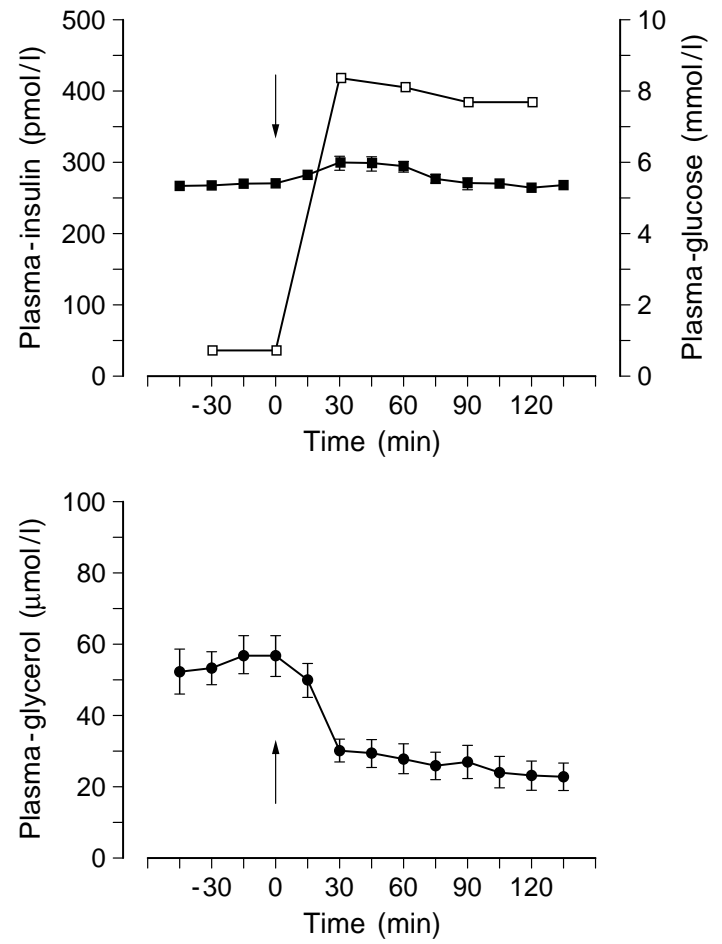

Fig. 1. The concentrations of plasma glucose $(\square)$, free insulin $(\square)$ (upper graph), and glycerol (O) (lower graph) in the fasting state and during a euglycaemic, hyperinsulinaemic clamp are shown. At time zero, a priming dose of insulin followed by a continuous insulin infusion was started (indicated by an arrow). The infusion of glucose was adjusted to maintain circulating glucose at the fasting level. Arterialized plasma samples were drawn in the basal state and then every 15 (glucose and glycerol) and every $30 \mathrm{~min}$ (insulin). Values are mean \pm SEM

concentration in the dialysate in the control probe decreased by $40 \%$ from the baseline level $(F=18.4$, $p<0.001)$. Post-hoc analysis revealed that the decrease was significant from 60 min onwards. When the selective PDE3-inhibitor amrinone was added to the perfusate, the antilipolytic effect of insulin was completely neutralized; instead a small increase in dialysate glycerol was observed $(F=5.5, p<0.001)$. Post-hoc analysis showed that this increase was significant from $90 \mathrm{~min}$ onwards. The decrease in adipose glycerol concentration was almost completely counteracted by the presence of the non-selective PDE-inhibitor theophylline, although a small decrease (about $10 \%$ ) was still observed during the insulin infusion $(F=5.8, p<0.001)$. The three curves were also simultaneously compared by two-way ANOVA. The overall time-course differed significantly $(F=11.1, p<0.001)$. The location of this difference was further tested with one-way ANOVA. The values between the probes differed significantly from $75 \mathrm{~min}$ onwards. Post-hoc analysis showed that values for all the probes differed from one another at these points. The selective inhibitor of PDE4 rolipram, did not counteract the glycerol-reducing action of insulin. As in the control probe, the glycerol concentration

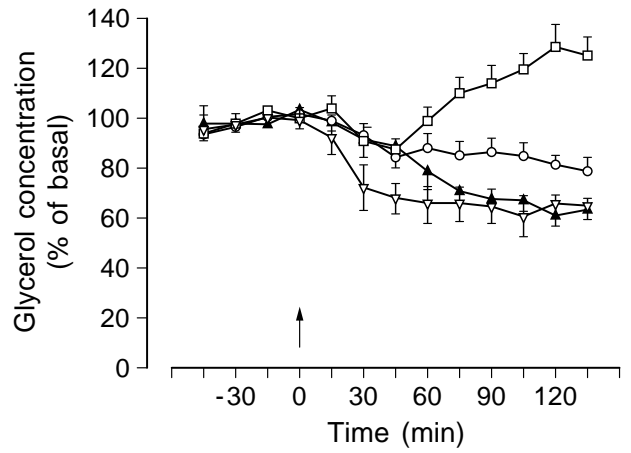

Fig. 2. The effect of insulin on the concentrations of glycerol in adipose tissue. The subcutaneous adipose tissue was microdialysed for 195 min with Ringer-ethanol solution $(n=9, \boldsymbol{\Delta})$ with the addition of amrinone $1.0 \mathrm{mmol} / \mathrm{l}(n=8, \square)$, theophylline $10 \mathrm{mmol} / \mathrm{l}(n=8, \bigcirc)$ or rolipram $0.1 \mathrm{mmol} / \mathrm{l}(n=6, \nabla)$. Fractions of dialysate were sampled every $15 \mathrm{~min}$ and analysed for glycerol. After a 60 min baseline sampling, a euglycaemic, hyperinsulinaemic clamp was started at time zero min., and continued for $135 \mathrm{~min}$. The concentrations of glycerol in dialysate and blood are expressed as a percentage of the basal level. Values are mean \pm SEM

in the dialysate decreased by $40 \%$ from the baseline level $(F=15.5, p<0.001)$. A post-hoc test showed that the decrease in glycerol was significant from 30 min onwards. On the basis of the statistical evaluations, we conclude that theophylline partly, and amrinone completely, counteracted the decrease in interstitial glycerol during the insulin infusion, whereas rolipram was ineffective in this respect.

Skeletal muscle glycerol. The basal level of glycerol concentration in skeletal muscle, while perfused with the control solution, was $29.6 \pm 3.3 \mu \mathrm{mol} / \mathrm{l}(n=9)$, with amrinone $28.7 \pm 2.2 \mu \mathrm{mol} / \mathrm{l}(n=9)$, with theophylline $24.1 \pm 2.6 \mu \mathrm{mol} / 1 \quad(n=8)$, with rolipram $23.4 \pm 5.5 \mu \mathrm{mol} / 1 \quad(n=6)$ and with dipyridamole $24.8 \pm 6.5 \mu \mathrm{mol} / 1(n=6)$. The baseline values did not differ significantly. A diagrammatic illustration of the changes in glycerol level expressed as percent of the basal level in skeletal muscle is shown in Figure 3 . The control probe, showed a gradual decrease in the glycerol level during the insulin infusion, reaching a maximum decrease of $33 \%$ from the basal level. The change over time in glycerol was significant $(F=7.6, p<0.001)$. A post-hoc test revealed that this change occurred from 30 min onwards. The addition of amrinone, rolipram or the selective PDE5-inhibitor dipyridamole to the perfusion medium had no obvious influence on the reduced glycerol concentration in skeletal muscle during hyperinsulinaemia. Thus the glycerol concentration in the dialysate of these probes decreased about as much as in the control probe during the insulin infusion. On the other hand, perfusion with theophylline abolished the glycerol-lowering effect of insulin-i.e., the dynamic changes in dialysate glycerol in the control compared to 


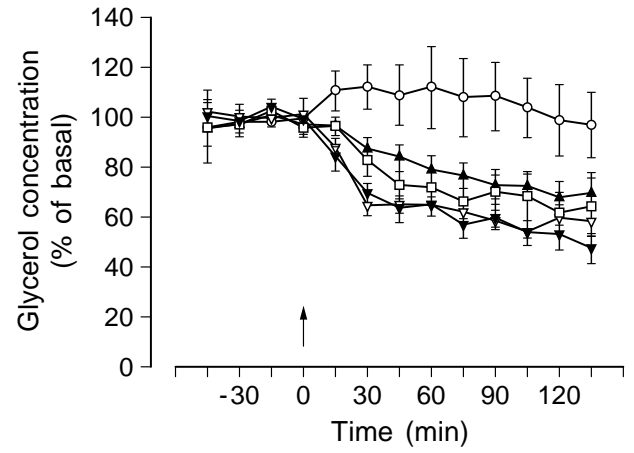

Fig. 3. The effect of insulin on the concentration of glycerol in skeletal muscle. The gastrocnemius muscle was microdialysed for 195 min with Ringer-ethanol solution $(n=9, \boldsymbol{\Delta})$ with the addition of amrinone $1.0 \mathrm{mmol} / \mathrm{l}(n=9, \square)$, theophylline $10 \mathrm{mmol} / \mathrm{l}(n=8, \bigcirc)$, rolipram $0.1 \mathrm{mmol} / \mathrm{l}(n=6, \nabla)$ or dipyridamole $1.0 \mathrm{mmol} / \mathrm{l}(n=6, \boldsymbol{\nabla})$. After a 60 minutes baseline sampling, a euglycaemic, hyper-insulinaemic clamp was started at time zero minutes and continued for 135 minutes. The concentrations of glycerol in dialysate and blood are expressed as a percentage of the basal level. Values are mean \pm SEM.

the theophylline probes differed significantly during the experiment $(F=7.1, p<0.001)$. There was no change over time in glycerol in the theophylline experiment $(F=0.4)$. The experiments were also compared at each timepoint by one-way ANOVA and post-hoc analysis. These tests revealed that the theophylline probe differed from the control probe and the probes with the other inhibitors from $15 \mathrm{~min}$ onwards. However, amrinone, rolipram, dipyridamole and control values did not differ significantly at any point. It was concluded from these statistical analyses that theophylline completely counteracted the glycerol-lowering effect of insulin, but inhibitors of PDE3,4 or -5 had no effect in this respect.

Comparison of glycerol levels in adipose tissue, skeletal muscle and blood. The basal glycerol level in adipose tissue was slightly higher than that in arterialized blood whereas the level in muscle was lower than that in blood. These differences do not reflect the true variation in glycerol in the three compartments, since microdialysis was performed under conditions of incomplete recovery. To perform frequent sampling, one must use a high perfusion speed, which reduces recovery. However, this probably does not affect the interpretation of our results since recovery is stable over time using a constant perfusion speed [26].

Monitoring of interstitial flow. The changes in interstitial flow were monitored by determining the escape of ethanol from the dialysate. The concentrations of ethanol in the collected outgoing and ingoing dialysates were analysed and expressed as the ethanol outflow/inflow ratio. Since the amount of ethanol leaving the probe through the membrane increases with tissue flow, the ratio will be inversely related to the

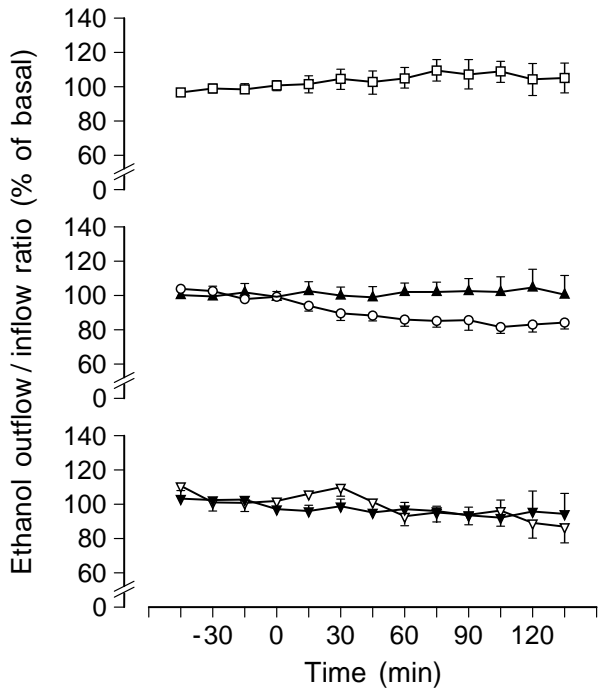

Fig.4. Effects on ethanol escape in skeletal muscle. Gastrocnemius muscle was microdialysed for $195 \mathrm{~min}$. Ringer's solution (control), $(n=9, \boldsymbol{\Delta})$ with the addition of amrinone $1.0 \mathrm{mmol} / \mathrm{l}(n=9, \square)$, theophylline $10 \mathrm{mmol} / \mathrm{l}(n=8, \bigcirc)$, rolipram $0.1 \mathrm{mmol} / \mathrm{l}(n=6, \nabla)$ or dipyridamole $1.0 \mathrm{mmol} / \mathrm{l}$ $(n=6, \boldsymbol{\nabla})$. The in- and outgoing ethanol concentrations were determined and the ethanol ratio was calculated, i.e., conc. ethanol ${ }_{\text {out }} /$ conc. ethanol $_{\text {in }} \times 100(\%)$. The figure depicts changes in the ethanol ratio from baseline values. Values are mean \pm SEM

flow in the vicinity of the probe membrane [17]. Changes in the skeletal muscle ethanol ratio are presented in Figure 4. As seen in the control probe, hyperinsulinaemia induced no detectable change in the ethanol ratio $(n=9)$. The addition of amrinone, rolipram or dipyridamole to the perfusion solvent was also ineffective in stimulating changes in interstitial flow. However, in the theophylline probe, a significant decrease in ethanol ratio was found $(F=4.7$, $p<0.001$ ), indicating an increase in interstitial flow. A post-hoc test showed that the decrease in ethanol ratio was significant from $60-120 \mathrm{~min}$. In adipose tissue, we detected no significant alteration over time in the ethanol ratio (figure not shown). The initial ethanol ratios in skeletal muscle were $21 \pm 1.6 \%$, $27 \pm 2.8 \%, 18 \pm 0.7 \%, 12 \pm 3.2 \%$ and $12 \pm 0.9 \%$ for the amrinone, theophylline, control, dipyridamole and rolipram probes, respectively. However, this difference was not significant. We also found that the ethanol ratios in the skeletal muscle control probe were markedly lower than those in adipose tissue, $18 \pm 1 \%$ and $48 \pm 2 \%$, respectively.

Activity of hormone-sensitive lipase. Since the assay used does not distinguish between inactivated and activated forms of the enzyme, the total HSL-activity was measured. The activity was related to the total amount of protein in the sub-cellular fraction. It was $2.7 \pm 0.4$ and $0.7 \pm 0.1 \mathrm{nmol} \times \mathrm{min}^{-1} \times \mathrm{mg}^{-1}(n=8)$ in the subcutaneous adipose tissue and gastrocnemius 
muscle, respectively. This fourfold difference in HSLactivity was significant $(p=0.0011)$.

Activity of phosphodiesterases. The tissue biopsies were also assayed for PDE-activity, expressed as the hydrolysed amount of cAMP, i.e., pmol cAMP $\times$ $\mathrm{min}^{-1} \times \mathrm{mg}^{-1}$. The activities of the different subtypes were related to the total amount of protein in the sample. The total activity of PDE3 in adipose was $36.8 \pm 6.4 \mathrm{pmol} \times \mathrm{min}^{-1} \times \mathrm{mg}^{-1}(48 \%$ of total PDE-activity) and in muscle $3.9 \pm 0.5 \mathrm{pmol} \times \mathrm{min}^{-1} \times \mathrm{mg}^{-1}$ (5.8\% of total PDE-activity). The approximate tenfold difference in PDE3-activity between the tissues was significant $(p=0.0016)$. Whereas the PDE3-activity in adipose tissue was equally distributed between the supernatant and pellet, the relatively small amount of PDE3-activity in skeletal muscle was located solely in the supernatant. Pooled adipose PDE4-activity was $8.5 \mathrm{pmol} \times \mathrm{min}^{-1} \times \mathrm{mg}^{-1}$. In skeletal muscle, PDE4-activity was $60.7 \pm 10.2$ pmol $\times$ $\mathrm{min}^{-1} \times \mathrm{mg}^{-1}$, which represents $80.5 \%$ of the total PDE-activity in this tissue. The major part of this activity was located in the supernatant. A minor contribution was found in the pellet when all muscle samples were pooled together $\left(5.4 \mathrm{pmol} \times \mathrm{min}^{-1} \times \mathrm{mg}^{-1}\right)$. The residual (i.e., non PDE3, -4 ) enzymatic activity was $31.2 \pm 7.9$ and $3.0 \pm 1.5 \mathrm{pmol} \times \mathrm{min}^{-1} \times \mathrm{mg}^{-1}$ in adipose tissue and skeletal muscle, respectively, representing 41 and $14 \%$ of the total PDE-activity in these two tissues. This may have been due to PDE1, $-2,-5$, -6 or -7 , or to still unidentified subclasses of PDE. None of those PDE families has been reported to be activated by insulin. Furthermore, selective inhibitors to be used on humans in vivo are not available. In vitro, PDE1 $\left(\mathrm{Ca}^{2+} /\right.$ calmodulin-stimulated PDE) and PDE2 (cGMP-stimulated PDE) were shown to be present in both adipose and skeletal muscle tissue biopsies, since $\mathrm{Ca}^{2+} /$ calmodulin $(10 \mathrm{mmol} /$ $\left.1 \times 0.1 \mathrm{mg}^{-1} \times \mathrm{ml}^{-1}\right)$ and $\mathrm{cGMP}(5 \mu \mathrm{mol} / \mathrm{l})$ were shown to increase PDE-activities. The increase in PDE-activity by the addition of $\mathrm{Ca}^{2+} /$ calmodulin was $2.6 \pm 0.2$-fold in adipose tissue and $2.7 \pm 0.7$-fold in skeletal muscle and by the addition of cGMP $3.5 \pm 0.8$-fold and 3.8 \pm 0.7 -fold in adipose tissue and skeletal muscle, respectively. It is not known whether the antilipolytic action of insulin in skeletal muscle could be mediated via either of these PDEs or via a still unidentified PDE.

\section{Discussion}

Recently, in vivo evidence has been presented in man for the existence of an important lipolysis process in skeletal muscle, which seems to be at least as active as in adipose tissue and can be inhibited by insulin [5]. Since insulin is the major antilipolytic hormone, the present in vivo study raised the question whether the antilipolytic effect of insulin is mediated by the same mechanism in human skeletal muscle as it is in subcutaneous adipose tissue, i. e., by activating phosphodiesterase-3 [4]. There is evidence of a different mechanism of insulin-induced antilipolysis in skeletal muscle compared to adipose tissue. For the first time, there are indications that insulin may act on a PDEisoform other than the type-3.

The interstitial fluid concentration of glycerol was used as an index of lipolysis. The reason for this is that glycerol is metabolized in adipose tissue during fasting conditions only to an insignificant extent [27, 28]. Glycerol released from the cell to the interstitial milieu therefore reflects intracellular lipolysis. Inflow of glycerol from the circulation to the interstitial fluid seems unlikely, since the interstitial concentration of glycerol is much higher than that in plasma [29]. The possibility of lipoprotein lipase influencing the glycerol released during hydrolysis of circulating lipoprotein-triacylglycerol is not relevant to this antilipolysis study because lipoprotein lipase in adipose tissue is activated by insulin and therefore should increase lipolysis. In the present study, this effect is obscured by hyperinsulinaemic-induced antilipolysis. Furthermore, arteriovenous studies show that only minor amounts of glycerol originate from hydrolysis of lipoproteins in adipose tissue in the fasting state [30].

The assumptions about adipose tissue glycerol mentioned above may be less certain as regards glycerol in skeletal muscle. The activity of glycerol kinase is low, but it exists in mammalian skeletal muscle [31]. A small uptake of glycerol occurs in muscle as shown in some forearm studies $[32,33]$. The changes in concentration of dialysate glycerol during insulin infusion in our experiments probably cannot be explained by re-uptake. The principal mechanism for transport of glycerol is passive diffusion, which is not known to be subjected to hormonal regulation to a major extent [34]. However, some decrease in the dialysate glycerol concentration in skeletal muscle, due to an insulin-induced fall in extracellular lipoprotein lipase activity, cannot be totally excluded, although the relative contribution to skeletal muscle energy needs of fatty acids, provided by lipoprotein lipase, is not known [35].

Interstitial flow may be of importance for removal of glycerol from the tissue, since changes in this may alter the glycerol concentration in the interstitial compartment independently of lipolysis [36]. An increase in interstitial flow could reduce glycerol in the interstitial fluid and give a false impression of inhibited lipolysis, and a decrease in flow could increase the interstitial glycerol concentration and give a false impression of stimulated lipolysis. Using the microdialysis ethanol technique, we found no evidence of any significant change in interstitial flow in these two tissues during systemic insulin infusion, except in the theophylline experiment in skeletal muscle, where a 
significant decrease in ethanol ratio was found. This agrees with recent microdialysis experiments in adipose tissue [4]. As regards skeletal muscle, hyperinsulinaemia clearly stimulates blood flow in the forearm and upper leg, as measured by the thermodilution technique or by plethysmography [37-40]. However, the latter methods cannot distinguish between flow in large vessels and interstitial flow. It is therefore possible that a change in blood flow in large blood vessels (not measured in this study) is not always followed by a change in interstitial flow (measured in this study). The ethanol ratio was lower in skeletal muscle than in adipose tissue, indicating a higher clearance of ethanol from the former tissue than from the latter. This difference is compatible with a relatively higher blood flow rate in skeletal muscle. It has recently been demonstrated in our laboratory that small systemic increases in adipose tissue blood flow ( $\approx 40 \%$ ) induced by heating, can be detected with the present microdialysis method [14]. The initial skeletal muscle ethanol ratio in the theophylline, experiment was higher than that found in the rolipram, and dipyridamole-experiments. Although not statistically significant (one-way ANOVA), our finding might be indicative of a difference in effect on interstitial fluxes between theophylline, rolipram and dipyridamole, respectively. It is well known that PDE-inhibitors are vasoactive compounds. This effect is executed through several different pathways, one being inhibition of PDEs. For instance, dipyridamole causes vasodilation through inhibition of both cAMP- and cGMP-PDEs, as well as through antagonism of adenosine uptake. Adenosine receptors are blocked by low concentrations of theophylline, whereas theophylline at a high concentration is a non-selective PDE-inhibitor [40]. However, the relative importance of various selective PDE-inhibitors compared to theophylline for variations in interstitial fluxes is not known. In the present study, we used the maximum lipolytic concentration of each drug, based on earlier in vivo experiments in adipose tissue [4, 15]. It has not been established if these are the most effective concentrations for inducing vasodilation in skeletal muscle. Furthermore, the qualitative action of a drug often changes as the concentration changes. It is possible that the effect on interstitial fluxes of theophylline and other PDE-inhibitors differs both with increasing concentrations and over time. The main aim with the present study was to investigate the importance of various PDEs in the regulation of skeletal muscle lipolysis. Effects of PDE-inhibitors on interstitial fluxes were not specifically addressed in this work but their regulatory role in controlling local blood flow certainly warrants further attention. However, when the ethanol ratio is constant, i.e., when interstitial flow is unchanged, changes in dialysate glycerol can be interpreted as changes in local production, according to the Fick principle. There- fore, the changes observed in dialysate glycerol are unlikely to be due to changes in interstitial flow but reflect the effects of theophylline, rolipram and dipyridamol, respectively, on glycerol output. The fact that the ethanol ratio decreased when theophylline was added, if anything, strengthens our conclusion, i. e., the glycerol concentration would be even higher if interstitial flow had been unaltered.

Bearing in mind the methodological discussion above, we interpret the findings of changes in glycerol concentration in the microdialysate, as being due mainly to alterations in intracellular lipolysis. As regards adipose tissue, the results are almost identical to previous findings in other subjects, using a slightly different microdialysis probe [4]. Thus, insulin lowered interstitial glycerol by about $40 \%$, which was counteracted by non-selective (theophylline) and by type-3-selective (amrinone) inhibitors of PDE. In the latter case, insulin stimulated lipolysis slightly. However, PDE4 inhibition did not influence the antilipolytic effect of insulin. Furthermore, determination of PDE-activity in adipose tissue revealed PDE3 as the main PDE-enzyme subtype. Taken together, these data clearly show that the major mechanism for insulin's antilipolytic effect on human adipose tissue in vivo is mediated by stimulation of PDE3.

Different and surprising results were obtained when skeletal muscle was investigated. In this tissue, insulin also lowered interstitial glycerol (by $33 \%$ ). Since no concentration-response experiments were performed, we do not know whether this is the maximum antilipolytic effect of the hormone in muscle. More important, however, was the finding that selective PDE3 inhibition had no influence on the antilipolytic action of insulin. The main PDE-activity in this tissue appeared to be PDE4. However, selective inhibitions of PDE4 and PDE5 were likewise ineffective in blocking insulin-induced antilipolysis in skeletal muscle. On the other hand, non-selective inhibition with theophylline completely abolished the antilipolytic effect of insulin in skeletal muscle. It is unlikely that this theophylline effect is due to interaction with adenosine receptors. As discussed elsewhere, theophylline only blocks adenosine receptors at low concentrations and inhibits PDE at high concentrations [41]. Furthermore, if the effect of theophylline on skeletal muscle was through adenosine receptors, amrinone would also counteract insulin effects in this tissue since amrinone is also an adenosine receptor blocker $[42,43]$. Instead, the findings strongly indicate that insulin inhibits lipolysis in muscle by stimulating one of several PDE isoenzymes other than PDE3, -4 or -5 . Unfortunately, one cannot identify the other critical PDE-subtype(s) in muscle by means of microdialysis. Inhibitors with some selectivity for PDE1 are available, but have not been used for human in vivo studies [3]. The measurements of total 
PDE activity in skeletal muscle suggested that approximately $14 \%$ was residual, i.e., not of PDE3 or -4 origin. This remaining activity probably contains a fraction that can be inhibited by insulin. It remains to be established which PDE isoforms, beside types 3 and 4, are present in human skeletal muscle.

As mentioned, it is difficult on the basis of in vivo measurements of interstitial glycerol to distinguish between lipolysis in myocytes and adipocytes in skeletal muscle [5]. For a number of reasons, however, we do not believe that our data concerning muscle lipolysis were due to lipolysis in adipocytes within the skeletal muscle tissue. First, it is very unlikely that fat cells interspersed in the muscle should behave differently to PDE3-inhibition in vivo, than fat cells would in adipose tissue. Secondly, the enzymatic ratios (adipose vs muscle) differed markedly for HSL (fourfold) and PDE3 (tenfold). Third, it seems unlikely that adipose cells and not muscle cells should take up amrinone. We do not know whether the observed skeletal muscle lipolysis was due to hydrolysis of intracellular triacylglycerols or of other intracellular glycerol-containing lipids, such as phospholipids or cholesterol esters. However, the finding that the regulation of lipolysis by insulin in adipose tissue differs from that in skeletal muscle has potential physiologic and pathophysiologic implications for non-esterified fatty acid metabolism. Muscle tissue is the major organ for utilization of non-esterified fatty acids in the body and, until recently, adipose tissue has been considered the main source for providing these lipids. However, the finding of marked lipolytic activity in skeletal muscle [5] with unique hormonal regulation (present findings) may suggest that the local production of fatty acids by intracellular lipolysis in myocytes may be as important for muscle function as delivery from distant depots. If this is true, local lipolysis may also influence the muscle in conditions with disturbed non-esterified fatty acid metabolism, such as diabetes, insulin resistance, dyslipoproteinaemia and hyperthyroidism. Hitherto, only PDE3 has been linked to insulin action among the PDE subtypes and their effect has been demonstrated only in fat cells [2]. The present study indicates a new target PDE for insulin in muscle. This subclass is not PDE3, -4 or -5 . Whether it is PDE1, $-2,-6,-7$ or a yet unidentified subclass remains to be established.

In summary, this study indicates a unique in vivo regulation of lipolysis by insulin in skeletal muscle in man. The hormone seems to inhibit lipolysis via a PDE which, in contrast to adipose tissue, is not of subtype-3 nor is it of type -4 or -5 .

Acknowledgements. This study was supported by grants from the Swedish Medical Research Council (19X-01034), HKH Kronprinsessan Lovisas förening för barnasjukvård and Stiftelsen Axel Tielmans Minnesfond, the Swedish Diabetes Association, the Swedish Medical Society and the foundations of
Nordic Insulin, Karolinska Institutet, Thuring, Söderberg, Martin Rind, Magnus Bergwall, Belvén and Påhlssons.

We thank Elizabeth Dungner, Britt-Marie Leijonhufvud, Katarina Hertel, Eva Sjölin and Kerstin Wåhlén for excellent technical and laboratory assistance.

\section{References}

1. Strålfors P, Olsson H, Belfrage P (1987) Hormone-sensitive lipase. In: The Enzymes. XVIII, Academic Press Inc. pp 147-177

2. Degerman E, Belfrage P, Manganiello VC (1997) Structure, localization and regulation of cGMP-inhibited phosphodiesterase (PDE3). J Biol Chem 272: 6823-6826

3. Beavo JA (1995) Cyclic nucleotide phosphodiesterases: functional implications of multiple isoforms. Physiol Rev 75: $725-748$

4. Hagstrom-Toft E, Bolinder J, Eriksson S, Arner P (1995) Role of phosphodiesterase III in the antilipolytic effect of insulin in vivo. Diabetes 44: 1170-1175

5. Maggs D, Jacob GR, Rife F et al. (1995) Interstitial fluid concentrations of glycerol, glucose, and amino acids in human quadricep muscle and adipose tissue. Evidence for significant lipolysis in skeletal muscle. J Clin Invest 96: 370-377

6. Holm C, Belfrage P, Fredrikson G (1987) Immunological evidence for the presence of hormone-sensitive lipase in rat tissues other than adipose tissue. Biochem Biophys Res Commun 148: 99-105

7. Small CA, Garton AJ, Yeaman SJ (1989) The presence and role of hormone-sensitive lipase in heart muscle. Biochem J 258(1):67-72

8. Movsesian MA, Komas N, Krall J, Manganiello VC (1996) Expression and activity of low Km, cGMP-inhibited cAMP phosphodiesterase in cardiac and skeletal muscle. Biochem Biophys Res Commun 225: 1058-1062

9. Lafontan M, Arner P (1996) Application of in situ microdialysis to measure metabolic and vascular responses in adipose tissue. Trends Pharmacol Sci 17: 309-313

10. Tossman U, Ungerstedt U (1986) Microdialysis in the study of extracellular levels of amino acids in the rat brain. Acta Physiol Scand 128: 9-14

11. Arner P, Bülow J (1993) Assessment of adipose tissue metabolism in man: comparison of Fick and microdialysis techniques. Clin Sci 85: 247-256

12. Hickner R, Rosdahl H, Borg I, Ungerstedt U, Jorfeldt L (1991) Ethanol may be used with the microdialysis technique to monitor blood flow changes in skeletal muscle: dialysate glucose concentration is blood flow-dependent. Acta Physiol Scand 143(3):355-356

13. Hickner R, Bone CD, Ungerstedt U, Jorfeldt L, Henriksson J (1994) Muscle blood flow during intermittent exercise: comparison of the microdialysis ethanol technique and 133Xe clearance. Clin Sci 86: 15-25

14. Fellander G, Linde B, Bolinder J (1996) Evaluation of the microdialysis ethanol technique for monitoring of subcutaneous adipose tissue blood flow in humans. Int $\mathrm{J}$ Obes Rel Metab Disorders 20: 220-226

15. Arner P, Hellmer J, Hagstrom-Toft E, Bolinder J (1993) Effect of phosphodiesterase inhibition with amrinone or theophylline on lipolysis and blood flow in human adipose tissue in vivo as measured with microdialysis. J Lipid Res 34:1737-1743

16. Weishaar RE, Burrows SD, Kobylarz DC, Quade MM, Evans DB (1986) Multiple molecular forms of cyclic nucle- 
otide phosphodiesterase in cardiac and smooth muscle and in platelets. Biochem Pharmacol 35: 787-800

17. Fuchi T, Rosdahl H, Hickner RC, Ungerstedt U, Henriksson J (1994) Microdialysis of rat skeletal muscle and adipose tissue: dynamics of the interstitial glucose pool. Acta Physiol Scand 151: 249-260

18. McGuire E, Helderman J, Tobin J, Andres R, Bergman R (1976) Effects of arterial versus venous sampling on glucose kinetics in man. J Appl Physiol 41: 65-73

19. De Fronzo RA, Tobin JD, Andres R (1979) Glucose clamp technique: a method for quantifying insulin secretion and resistance. Am J Physiol. 237: E214-E223

20. Fredrikson G, Stralfors P, Nilsson NO, Belfrage P (1981) Hormone-sensitive lipase from adipose tissue of rat. Methods Enzymol 71 Pt C:636-646

21. Frayn KN, Langin D, Holm C, Belfrage P (1993) Hormone-sensitive lipase: quantitation of enzyme activity and mRNA level in small biopsies of human adipose tissue. Clin Chim Acta 216: 183-189

22. Manganiello VC, Murad F, Vaughan M (1971) Effects of lipolytic and antilipolytic agents on cyclic $3{ }^{\prime}, 5^{\prime}$-adenosine monophosphate in fat cells. J Biol Chem 246(7): 2195-2202

23. Kaddish A, Little R, Sternberg J (1961) A new and rapid method for the determination of glucose by measurement of the rate of oxygen consumption. Clin Chem 14: 116-131

24. Hellmer J, Arner P, Lundin A (1989) Automatic luminometric kinetic assay of glycerol for lipolysis studies. Anal Biochem 177: 132-137

25. Bernt E, Gutman I (1974) Determination of ethanol with alcohol dehydrogenase and NAD. In: Bergmeyer HU (ed) Methods of enzymatic analysis. Verlag Chemie Weinheim, pp 1499-1505

26. Arner P, Kriegholm E, Engfeldt P, Bolinder J (1990) Adrenergic regulation of lipolysis in situ at rest and during exercise. J Clin Invest 85: 893-898

27. Frayn KN, Humphreys SM, Coppack SW (1995) Fuel selection in white adipose tissue. Proc Nutr Soc 54: 177-189

28. Coppack SW, Jensen MD, Miles JM (1994) In vivo regulation of lipolysis in humans. J Lipid Res 35: 177-193

29. Jansson PA, Smith U, Lonnroth P (1990) Interstitial glycerol concentration measured by microdialysis in two subcutaneous regions in humans. Am J Physiol 258:E918-E922
30. Coppack SW, Fisher RM, Gibbons GF et al. (1990) Postprandial substrate deposition in human forearm and adipose tissues in vivo. Clin Sci 79: 339-348

31. Newsholme E, Taylor K (1968) Glycerol kinase activities in muscles from vertebrates and intervertebrates. Biochem $\mathrm{J}$ 112: 465-474

32. Natali A, Buzzigoli G, Taddei S et al. (1990) Effects of insulin on hemodynamics and metabolism in human forearm. Diabetes 39: 490-500

33. Frayn KN, Coppack SW, Humphreys SM (1991) Glycerol and lactate uptake in human forearm. Metabolism 40: 1317-1319

34. Lin EC (1977) Glycerol utilization and its regulation in mammals. Annu Rev Biochem 46: 765-795

35. Eckel RH (1989) Lipoprotein lipase: a multifunctional enzyme relevant to common metabolic diseases. N Engl J Med 320: 1060-1068

36. Enoksson S, Nordenstrom J, Bolinder J, Arner P (1995) Influence of local blood flow on glycerol levels in human adipose tissue. Int J Obes Rel Metab Disorders 19: 350-354

37. Yki-Jarvinen H, Young AA, Lamkin C, Foley JE (1987) Kinetics of glucose disposal in whole body and across the forearm in man. J Clin Invest 79: 1713-1719

38. Laakso M, Edelman SV, Brechtel G, Baron AD (1990) Decreased effect of insulin to stimulate skeletal muscle blood flow in obese man. A novel mechanism for insulin resistance. J Clin Invest 85: 1844-1852

39. Creager MA, Liang CS, Coffman JD (1985) Beta adrenergic-mediated vasodilator response to insulin in the human forearm. J Pharmacol Exp Ther 235: 709-714

40. Baron AD, Steinberg HO, Chaker H, Leaming R, Johnson A, Brechtel G (1995) Insulin-mediated skeletal muscle vasodilation contributes to both insulin sensitivity and responsiveness in lean humans. J Clin Invest 96: 786-792

41. Schwabe U, Ukena D, Lohse MJ (1985) Xanthine derivates as antagonists at $\mathrm{A}_{1}$ and $\mathrm{A}_{2}$ adenosine receptors. Arch Pharmacol 330: 212-221

42. Lönnqvist F, Wennlund A, Arner P (1989) Antilipolytic effects of insulin and adenylate cyclase inhibitors on isolated human fat cells. Int J Obes 13: 137-146

43. Fredholm BB (1978) Local regulation of lipolysis in adipose tissue by fatty acids, prostaglandins and adenosine. Med Biol 56: 249-261 